\title{
Synthesis and bioevaluation of novel heterostilbenes as potential anti-inflammatory and anti-angiogenic agents
}

\author{
Chien-Ming Huang ${ }^{1,2}$, An-Rong Lee ${ }^{3}$, Jiajiu Shaw ${ }^{4}$, Wen-Hsin Huang ${ }^{3^{*}}$ \\ ${ }^{1}$ Division of Pharmacy, Cheng-Hsin General Hospital, Taipei, China \\ ${ }^{2}$ Department of Nursing, Cardinal Tien College of Healthcare \& Management, Taipei, China \\ ${ }^{3}$ School of Pharmacy, National Defense Medical Center, Taipei, China; \\ *Corresponding Author: wenhsin@ndmctsgh.edu.tw \\ ${ }^{4}$ JAK3 Pharma, Inc., Ann Arbor, USA
}

Received 10 April 2013; revised 10 May 2013; accepted 10 June 2013

Copyright (C) 2013 Chien-Ming Huang et al. This is an open access article distributed under the Creative Commons Attribution License, which permits unrestricted use, distribution, and reproduction in any medium, provided the original work is properly cited.

\begin{abstract}
Novel heterocyclic analogs of resveratrol, (E)stilbene analogs, were readily prepared by conjugation of a heterocyclic benzothiazolium moiety with the core styrene structure of resveratrol and evaluated for their biological properties. The results showed that these analogs were superior to resveratrol in 1) anti-angiogenesis in vitro, 2) nitric oxide inhibition in vitro, and 3) inhibition of carrageenan-induced edema in vivo. In summary, introduction of a heterocyclic benzothiazolium moiety to replace one of two aromatic rings from the core stilbene structure of resveratrol provided beneficial biological properties and is worthy of further investigation.
\end{abstract}

Keywords: Resveratrol Analogs; Benzothiazolium; Anti-Angiogenesis; Carrageenan-Induced Edema

\section{INTRODUCTION}

Inflammation is a symptom standing for cell injury that plays a housekeeping role in diseases triggered by inflammatory cells such as macrophages, microglial, and mast cells that acutely or chronically mediate and/or aggravatedly activate pathology inducing the primary response of the innate immune system to damage and to promote disease progression.

As an effective defense in biology, the inflammatory response usually lacks specificity and overreacts to cause significant bystander damage which activated in response to pathogens or tissue damage and amplified the inflammatory response to induce production of inflam- matory mediators including nitric oxide, reactive oxygen species, proinflammatory cytokine s (such as IL-1, NFkB, AP-1, IL-6, IL-17, IL-18, TGF $\beta$, and TNF $\alpha$ ), chemokines (MMPs, MCP-1) and prostaglandins, associated with vicious circle of cell death, and so on [1,2].

Nitric oxide (NO), one of reactive nitrogen species, is an endothelial survival factor, it inhibits apoptosis, enhances endothelial cell proliferation and/or migration, and might increase the VEGF or fibroblast growth factor expressions in part, but inducible nitric oxide (NO) production by activated inflammatory cells which further contribute to tissue damage or degradation, and/or ultimate cell death. NO is also one of angiogenesis mediators and vascular endothelial growth factor (VEGF) mutually triggers the release of NO from cultured human umbilical venous endothelial cells and even up-regulates the expression of nitric oxide synthase (NOS) $[3,4]$.

The bio-complexities of NO-angiogenesis pathway become pathological evidences related to neovascularization in the convoluted biological context of arthritis, atherosclerosis, and tumor ever more, whereas angiogenic factors accelerate it $[5,6]$.

Most biological processes such as angiostatin generated from the degradation of plasminogen by matrix metalloproteinases (MMPs), a known endogenous inhibitor of angiogenesis, modulate response to keep homeostasis, however, an issued that NO may trigger countervailing effects to suppress the production of angiostatin [7]. Investigations issued that angiogenesis is attenuated when NO bioactivity is reduced. Furthermore, anti-inflammatory mechanisms include repression of proinflammatory mediators including NO, cytokines, chemokines, matrix metalloproteases, and prostaglandins in inflammatory cells $[5,6]$. 
Resveratrol, 3,5,4'-trihydroxy-trans-stilbene (1), is a polyphenol found in grapes, blue berries, peanuts, and a number of other plants [8-10]. Resveratrol exhibits a variety of useful biological properties including antileukemic, antibacterial, antifungal, antiplatelet aggregation, coronary vasodilator, antioxidative, and antiinflammatory activities and so on [11-13]. In the specific field of arthritis, it was recently reported that resveratrol inhibits the proliferation of synoviocytes in rheumatoid arthritis (RA) in vitro [14]. Elmali et al. suggested that intra-articular injection of resveratrol may protect cartilage against the development of experimentally induced inflammatory arthritis [15]. Resveratrol has been reported to inhibit nitric oxide production by lipopolysaccharide-activated brain microglia [16]. Resveratrol revealed effectively anti-angiogenic action as well [17].

Due to the beneficial effects of resveratrol, many attempts to modify its structure have been made by scientists to further improve its water-solubility and biological activities. A number of hetercyclic resveratrol analogs have been reported and some of them have shown interesting biological activities [18-22]. However, for most of the reported analogs, the $(E)$-stilbene core structure is either maintained intact or only slightly modified.

We hypothesized that it is not necessary to maintain the core structure of resveratrol in order to improve its biological activities. Based on this hypothesis, we introduced a novel heterocyclic benzothiazolium moiety into the $(E)$-stilbenes, made four analogs first, and investigated their biological properties.

\section{METHODS}

\subsection{Chemistry}

Research chemicals were purchased from Sigma-Aldrich or Alfa Aesar and used at least 95\% purity without further purification. The reference compound, resveratrol (99\% GC purity), was purchased from Sigma-Aldrich. Reactions were monitored by thin-layer chromatography (TLC) on silica gel plates (60 F254; Merck) visualizing with ultraviolet light or iodine. Melting points were taken in open capillary tubes on a Buchi-530 melting point apparatus and are uncorrected. 1H-NMR spectra were determined on a Varian Gemini-300 NMR instrument. Chemical shifts $(\delta)$ are reported in parts per million (ppm) relative to tetramethylsilane (TMS) as an internal standard; coupling constants $(J)$ are shown in hertz $(\mathrm{Hz})$ and signals are described as s (singlet), d (doublet), t (triplet), and $\mathrm{m}$ (multiplet). IR spectra were recorded on a Perkin-Elmer FTIR 1610 series infrared spectrophotometer in $\mathrm{KBr}$ discs. Fast atom bombardment (FAB) mass spectra were recorded using a JEOL-SX102A (GC/LC/MS) spectrometer. Only peaks of significant relative intensity are presented in the form of $m / z$ (intensity relative to base peak). Elemental analyses for carbon, hydrogen, nitrogen and sulfur were performed in the Instrument Center of the National Science Counsel at the National Taiwan University using HERAEUS VarioEL analyzer.

3-Ethyl-2-methylbenzothiazolium bromide (2).

2-Methylbenzothiazole $(1.5 \mathrm{~g}, 10 \mathrm{mmol})$ was reacted with ethyl bromide $(1.5 \mathrm{ml}, 20 \mathrm{mmol})$ over $5 \mathrm{~h}$ in a special closed glass tube (explosive-proof) using CEM microwave reactor under 250 watts, $120^{\circ} \mathrm{C}$, to obtain the product as precipitate. Filter and wash the precipitate with ethyl ether or dichloromethane to obtain the pure product $(1.47 \mathrm{~g}, 57 \%$ yield). The product is soluble in acetone and in water. Alternative method without the microwave reactor: 2-methylbenzothiazole (1.5 g, 10 mmol) was reacted with ethyl bromide $(15 \mathrm{ml}, 200 \mathrm{mmol})$ in $100 \mathrm{ml}$ of acetonitrile (as the solvent) under reflux over $72 \mathrm{~h}$ to obtain the product as precipitate. Filter and wash the precipitate with ethyl ether or dichloromethane to obtain the title compound ( $0.89 \mathrm{~g}, 32 \%$ yield $).)$; mp $240^{\circ} \mathrm{C}-241^{\circ} \mathrm{C} ;{ }^{1} \mathrm{H}-\mathrm{NMR}\left(300 \mathrm{MHz}, \mathrm{DMSO}-d_{6}\right) \delta: 1.44$ $(3 \mathrm{H}, \mathrm{t}, J=7.2 \mathrm{~Hz}), 3.19(3 \mathrm{H}, \mathrm{s}), 4.75(1 \mathrm{H}, \mathrm{q}, J=7.2 \mathrm{~Hz})$, $7.78(1 \mathrm{H}, \mathrm{t}, J=8.4 \mathrm{~Hz}), 7.88(1 \mathrm{H}, \mathrm{t}, \mathrm{J}=8.4 \mathrm{~Hz}), 8.32$ $(1 \mathrm{H}, \mathrm{d}, J=8.4 \mathrm{~Hz}), 8.43(1 \mathrm{H}, \mathrm{d}, J=8.4 \mathrm{~Hz})$, FAB-MS $m / z(\%): 178\left(\mathrm{M}^{+}-\mathrm{Br}, 19 \%\right)$.

$N$-Ethyl-2-[(E)-2-(2'-hydroxy-4'-methoxyphenyl)viny 1] benzothiazolium bromide (3).

To $15 \mathrm{ml}$ of $n$-propanol was added $258 \mathrm{mg}(1 \mathrm{mmol})$ of $2,228 \mathrm{mg}$ (1.5 mmol) of 2-hydroxy-4-methoxybenzaldehyde, and catalytic amount of zinc chloride. The mixture was refluxed for $3 \mathrm{~h}$. At the completion of the reaction, $30 \mathrm{ml}$ of ether/hexane $(1 / 1, \mathrm{v} / \mathrm{v})$ was added to the solution to precipitate the crude product. $\mathrm{H}_{2} \mathrm{O} / \mathrm{Me}-$ $\mathrm{OH} /$ acetone $(1 / 1 / 2, \mathrm{v} / \mathrm{v} / \mathrm{v})$ was used to recrystallize highly purified product. Bricky red powder; yield $0.36 \mathrm{~g}$ (92\%); mp $168^{\circ} \mathrm{C}-170^{\circ} \mathrm{C}$; ${ }^{1} \mathrm{H}-\mathrm{NMR}$ (300 MHz, DM$\left.\mathrm{SO}-d_{6}\right) \delta: 1.44(3 \mathrm{H}, \mathrm{t}, J=7.2 \mathrm{~Hz}), 3.81(3 \mathrm{H}, \mathrm{s}), 4.83(1 \mathrm{H}$, $\mathrm{q}, J=7.2 \mathrm{~Hz}), 6.52(1 \mathrm{H}, \mathrm{d}, J=2.1 \mathrm{~Hz}), 6.60(1 \mathrm{H}, \mathrm{dd}, J=$ $8.7,2.1 \mathrm{~Hz}), 7.23(1 \mathrm{H}, \mathrm{t}, J=7.2 \mathrm{~Hz}), 7.81(1 \mathrm{H}, \mathrm{d}, J=$ $15.6 \mathrm{~Hz}), 7.82(1 \mathrm{H}, \mathrm{t}, J=7.2 \mathrm{~Hz}), 8.00(1 \mathrm{H}, \mathrm{d}, J=8.7$ $\mathrm{Hz}), 8.23(1 \mathrm{H}, \mathrm{d}, J=15.6 \mathrm{~Hz}), 8.24(1 \mathrm{H}, \mathrm{d}, J=8.7 \mathrm{~Hz})$, $8.33(1 \mathrm{H}, \mathrm{d}, J=8.1 \mathrm{~Hz}), 10.59(1 \mathrm{H}, \mathrm{s})$; IR $(\mathrm{KBr}) \mathrm{cm}^{-1}$ : 3150 (br, OH), 1597, 1573, 1513, 1440; FAB-MS m/z (\%): $313\left(\mathrm{M}^{+}-\mathrm{Br}, 27 \%\right)$. Anal. $\left(\mathrm{C}_{18} \mathrm{H}_{18} \mathrm{BrNO}_{2} \mathrm{~S} \cdot 3.5 \mathrm{H}_{2} \mathrm{O}\right)$ C, H, N, S.

$N$-Ethyl-2-[(E)-2-(3',4',5'-trimethoxyphenyl)vinyl]be nzothiazolium bromide (4).

The same method for 3 was used except 2-hydroxy4-methoxybenzaldehyde was replaced by $247.5 \mathrm{mg}$ (1.5 mmol) of 3,4,5-trimethoxybenzaldehyde. Earth yellow powder; yield $0.41 \mathrm{~g}(94 \%) ; \mathrm{mp} 240^{\circ} \mathrm{C}-242^{\circ} \mathrm{C}$; ${ }^{1} \mathrm{H}-\mathrm{NMR}\left(300 \mathrm{MHz}, \mathrm{DMSO}-d_{6}\right) \delta: 1.48(3 \mathrm{H}, \mathrm{t}, J=7.2$ $\mathrm{Hz}), 3.77(3 \mathrm{H}, \mathrm{s}), 3.90(6 \mathrm{H}, \mathrm{s}), 5.00(1 \mathrm{H}, \mathrm{q}, J=7.2 \mathrm{~Hz})$, 
$7.42(2 \mathrm{H}, \mathrm{s}), 7.79(1 \mathrm{H}, \mathrm{t}, J=8.1 \mathrm{~Hz}), 7.88(1 \mathrm{H}, \mathrm{t}, J=8.1$ $\mathrm{Hz}), 7.93(1 \mathrm{H}, \mathrm{d}, J=15.9 \mathrm{~Hz}), 8.19(1 \mathrm{H}, \mathrm{d}, J=15.9 \mathrm{~Hz})$, $8.30(1 \mathrm{H}, \mathrm{d}, J=8.7 \mathrm{~Hz}), 8.45(1 \mathrm{H}, \mathrm{d}, J=8.7 \mathrm{~Hz})$. IR $(\mathrm{KBr}) \mathrm{cm}^{-1}$ : 3421 (br, OH), 1610, 1576, 1503, 1452. FAB-MS $m / z(\%): 357\left(\mathrm{M}^{+}-\mathrm{Br}, 57 \%\right)$. Anal. $\left(\mathrm{C}_{20} \mathrm{H}_{22} \mathrm{Br}-\right.$ $\left.\mathrm{NO}_{3} \mathrm{~S} \cdot 3 \mathrm{H}_{2} \mathrm{O}\right) \mathrm{C}, \mathrm{H}, \mathrm{N}, \mathrm{S}$.

$N$-Ethyl-2-[(E)-2-(3',5'-dimethoxy-4'-hydroxyphenyl) vinyl]benzothiazolium bromide (5).

The same method for 3 was used except 2-hydroxy-4-methoxybenzaldehyde was replaced by $273 \mathrm{mg}(1.5$ mmol) of 3, 5-dimethoxy-4-hydroxybenzalde hyde (mmol). Scarlet powder; yield $0.32 \mathrm{~g}(89 \%)$; mp $238^{\circ} \mathrm{C}-$ $240^{\circ} \mathrm{C}$. ${ }^{1} \mathrm{H}-\mathrm{NMR}\left(300 \mathrm{MHz}, \mathrm{DMSO}-d_{6}\right) \delta: 1.46(3 \mathrm{H}, \mathrm{t}, J$ $=6.9 \mathrm{~Hz}), 3.88(6 \mathrm{H}, \mathrm{s}), 4.95(1 \mathrm{H}, \mathrm{q}, J=6.9 \mathrm{~Hz}), 7.41$ $(2 \mathrm{H}, \mathrm{s}), 7.75(1 \mathrm{H}, \mathrm{t}, J=7.2 \mathrm{~Hz}), 7.80(1 \mathrm{H}, \mathrm{d}, J=15.9$ $\mathrm{Hz}), 7.84(1 \mathrm{H}, \mathrm{t}, J=7.2 \mathrm{~Hz}), 8.15(1 \mathrm{H}, \mathrm{d}, J=15.9 \mathrm{~Hz})$, $8.24(1 \mathrm{H}, \mathrm{d}, J=8.1 \mathrm{~Hz}), 8.40(1 \mathrm{H}, \mathrm{d}, J=8.1 \mathrm{~Hz}), 9.75$ (1H, s). IR (KBr) cm ${ }^{-1}: 3427$ (br, OH), 1585, 1508, 1443. FAB-MS $m / z(\%)$ : $343\left(\mathrm{M}^{+}-\mathrm{Br}, 48 \%\right)$. Anal. $\left(\mathrm{C}_{19} \mathrm{H}_{20} \mathrm{Br}-\right.$ $\left.\mathrm{NO}_{3} \mathrm{~S} \cdot 3 \mathrm{H}_{2} \mathrm{O}\right) \mathrm{C}, \mathrm{H}, \mathrm{N}, \mathrm{S}$.

$N$-Ethyl-2-[(E)-2-(4'-hydroxy-3'-methoxyphenyl)viny 1]benzothiazolium bromide (6).

The same method for 2 was used except 2-hydroxy-4-methoxybenzaldehyde was replaced by $228 \mathrm{mg}(1.5$ mmol) of 3-methoxy-4-hydroxybenzaldehyde. Brick red powder; yield $0.35 \mathrm{~g}(89 \%) ; \mathrm{mp} 148^{\circ} \mathrm{C}-150^{\circ} \mathrm{C}$. ${ }^{1} \mathrm{H}-\mathrm{NMR}\left(300 \mathrm{MHz}, \mathrm{DMSO}-d_{6}\right) \delta: 1.46(3 \mathrm{H}, \mathrm{t}, J=7.2$ $\mathrm{Hz}), 3.83$ (3H, s), 4.94 (1H, q, $J=7.2 \mathrm{~Hz}), 6.94(1 \mathrm{H}, \mathrm{d}, J$ $=8.1 \mathrm{~Hz}), 7.57(1 \mathrm{H}, \mathrm{dd}, J=8.1,2.1 \mathrm{~Hz}), 7.66(1 \mathrm{H}, \mathrm{d}, J=$ $2.1 \mathrm{~Hz}), 7.75(1 \mathrm{H}, \mathrm{t}, J=7.5 \mathrm{~Hz}), 7.80(1 \mathrm{H}, \mathrm{d}, J=15.3$ $\mathrm{Hz}), 7.84(1 \mathrm{H}, \mathrm{t}, J=7.5 \mathrm{~Hz}), 8.15(1 \mathrm{H}, \mathrm{d}, J=15.3 \mathrm{~Hz})$, $8.24(1 \mathrm{H}, \mathrm{d}, J=8.4 \mathrm{~Hz}), 8.39(1 \mathrm{H}, \mathrm{d}, J=7.8 \mathrm{~Hz}), 10.29$ (1H, s). IR (KBr) cm ${ }^{-1}: 3434$ (br, OH), 1583, 1511, 1440. FAB-MS $m / z(\%)$ : $313\left(\mathrm{M}^{+}-\mathrm{Br}, 43 \%\right)$. Anal. $\left(\mathrm{C}_{18} \mathrm{H}_{18} \mathrm{Br}-\right.$ $\left.\mathrm{NO}_{2} \mathrm{~S} \cdot 4 \mathrm{H}_{2} \mathrm{O}\right) \mathrm{C}, \mathrm{H}, \mathrm{N}, \mathrm{S}$.

\subsection{In-Vitro Biological Studies}

\subsubsection{Nitric Oxide Inhibition}

The mouse BALB/c macrophage cell line, RAW 264.7 BCRC No. 60001 (identical to ATCC number TIB-71), was obtained from Bioresource Collection and Research Center, Taiwan. The cells were maintained according to the protocols being cultured in $50 \mathrm{~cm}^{2}$ plastic flasks (Nunc, Roskilde, Denmark) with the medium renewed every 3 days. LPS (from Escherichia coli, serotype 0127:B8), trypan blue and all the other chemicals, unless otherwise specified, were purchased from Aldrich-Sigma Chemical Company (St. Louis, MO, USA).

Determination of cell viability by an MTT assay. To evaluate the cell viability, a methylthiazoletetrazolium bromide (MTT) assay was conducted by the standard method in our laboratory. Incubation was performed after pretreating with a combination of the test compounds, in stock concentrations of $25,50,100$, and up to $200 \mu \mathrm{M}$ in dimethyl sulfoxide, and LPS $(100 \mathrm{ng} / \mathrm{ml})$ in normal saline for $24 \mathrm{~h}$. Untreated cells were used as the control.

Nitrite quantification. The cells were cultured with or without a pretreatment by the test compounds and resveratrol of $25,50,100$, and up to $200 \mu \mathrm{M}$ as already described. Each value is the mean \pm SEM of three determinations. ${ }^{*} p<0.05$, each value was compared with or without the LPS-stimulated group.

The production of NO was determined by measuring the accumulated level of nitrite in the culture supernatant with the Griess reagent in LPS-stimulated macrophage cells. A quantity of $100 \mu \mathrm{l}$ of a sample aliquot were mixed with $100 \mu \mathrm{l}$ of the Griess reagent $(0.1 \% N$-(1-naphthyl)ethylenediamine, $1 \%$ sulfanilamide, and $2.5 \%$ phosphoric acid) in a 96-well plate and then incubated at $25^{\circ} \mathrm{C}$ for $10 \mathrm{~min}$. The absorbance at $550 \mathrm{~nm}$ was measured with an ELISA reader (MR 700, Dynatech Laboratories, Alexandria, VA, USA). $\mathrm{NaNO}_{2}$ was used as the standard to calculate the nitrite concentration.

\subsubsection{Anti-Angiogenesis Study}

Capillary-tube formation was assayed using the angiogenesis kits (Kurabo, Okayama, Japan) according to the manufacturer's instruction. Briefly, human umbilical vein endothelial cells (HUVECs) cocultured with normal human dermal fibroblasts (NHDF), which a cultural kit originally developed by Kurabo Co. Ltd., Okayama, Japan, onto 24-well plate were incubated either with or without test compounds and resveratrol respectively at appropriate concentrations $(1-100 \mu \mathrm{M})$ for $11 \mathrm{~d}$ (media replacement was performed at $\mathrm{d} 1,4,7$, and 9). The cells were thereafter fixed with $70 \%$ cold ethanol, incubated with mouse antihuman CD31 antibody followed by incubation with an alkaline phosphatase conjugate goat antimouse antibody, and then stained with 5-bromo-4-chloro-3-indolyl phosphate/nitro blue tetrazolium to visualize tube network at d-11, respectively. In each assay, randomly selected five fields of view in each well were captured by digital camera under the light microscopy on x40 magnification. The analysis of tube formation was then carried out by measuring total area and length of tubes per well using analytical software (by Kurabo).

\subsubsection{In-Vivo Carrageenan-Induced Paw Edema Study}

In this study, $\lambda$-carrageenan was used to stimulate the inflammation on the rear footpad of the rats. Male albino Wistar rats (183 - 218 g) 4 to 6 weeks old were housed and cared under the guidelines of the Institutional Ani mal Care and Use Committee at the National Defense Medical Center, Taiwan. The rats were assigned to groups. For each group, 3 rats were used and marked on 
the tails. one of them being the control. In order to induce inflammation, $50 \mu \mathrm{l}$ of a $1 \% \lambda$-carrageenan solution in normal saline was injected into the right hind paw subplantar tissue. The development of paw edema was measured plethysmographically (Basile 7140 plethysmometer, Ugo, Varese, Italy) and recorded prior to this administration. One hour before the $\lambda$-carrageenan challenge, a sample preparation $(20 \mathrm{mg} / \mathrm{kg}$ in CMC) includes resveratrol (1) and its analogs 3, 4, 5 and 6. Before carrageenan treatment, the volume of each left footpad was measured $\left(V_{0}\right)$. Each rat was injected i.p. with the followings: 1) Control Group: medium only; 2) Testing Groups (one group for each compound), compound suspension in carboxymethyl cellulose (CMC) $(20 \mathrm{mg} / \mathrm{kg})$; and 3) Comparison group: resveratrol suspension in CMC $(20 \mathrm{mg} / \mathrm{kg})$ was injected i.p. into the rat in the test group. After the $\lambda$-carrageenan challenge, each paw volume (ml) was measured hourly up to $5 \mathrm{~h}$. The percentage of paw edema and the inhibition of inflammation were calculated. Edema rate $(E \%)$ was calculated as follows: $E \%=\left(V_{t}-V_{0}\right) / V_{0} \times 100:$ volume of hind paw before $1 \%$ $\lambda$-carrageenan administration; $V$ : volume of hind paw after $1 \%$ carrageenan administration at $t \mathrm{~h}$. Percentage of inhibition (I\%) was determined as follows:

$I \%=\left(E_{c}-E_{t}\right) / E_{c} \times 100 ; E_{c}$ : edema rate of control group; Et: edema rate of the respective test compound at $t$ h.

\subsection{Statistical Analysis}

Each experimental data value is expressed as the mean \pm SEM. The statistical significance of differences was assessed with an analysis of variance (ANOVA), followed by Tukey's test or Student's test between two groups. Differences with $p$ values of less than 0.05 are considered statistically significant. The statistical significance of differences was assessed with an analysis of variance (ANOVA), followed by Tukey's test or Student's test between two groups. Each value represents the mean \pm SEM, $\mathrm{n}=5,{ }^{*} P<0.05$ compared with the control (0.1 ml normal saline), ${ }^{* *} P<0.05$ compared with positive control (ibuprofen), respectively.

\section{RESULTS}

\subsection{Synthesis}

Two methods were utilized for the synthesis of 3-ethyl-2-methylbenzothiazolium bromide 2): a) in a CEM Discover microwave reactor, and b) by a traditional reflux, in $57 \%$ and $32 \%$ yields, respectively. Compound 2 was then used as the key starting material to react with the respective benzaldehydes to synthesize four heterocyclic resveratrol analogs 3 - 6 (Scheme 1 and Figure 1).

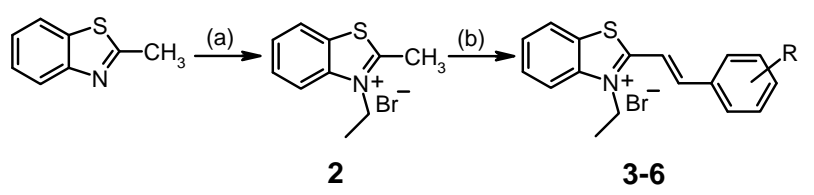

Scheme 1. Synthesis of resveratrol analogs ${ }^{\mathrm{a}} \cdot{ }^{\mathrm{a}}$ Reagents and conditions: (a) $\mathrm{C}_{2} \mathrm{H}_{5} \mathrm{Br}$ in CEM microwave under 250 watts, $120^{\circ} \mathrm{C}$. for $5 \mathrm{hr}$. (b) reacted with respective benzaldehyde and trace amount of $\mathrm{ZnCl}_{2}$ in $n$-propanol and reflux for $3 \mathrm{hr}$.

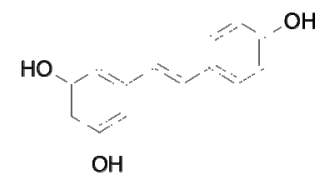

resveratrol

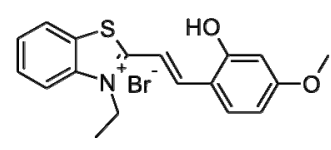

3

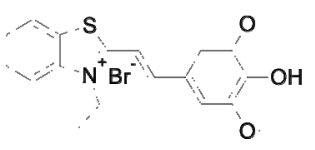

5

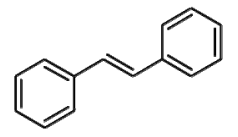

(E)-stilbene

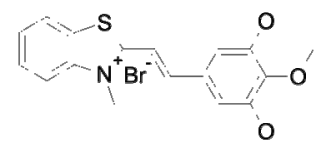

4

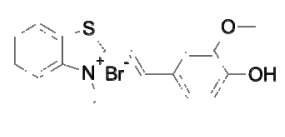

6
Figure 1. Structures of resveratrol, $(E)$-stilbene, and compounds $3-6$.

\subsection{Biological Evaluation}

\subsubsection{In-Vitro Nitric Oxide Inhibition (Based on Nitrite)}

These analogs 3 - 6 compared to resveratrol were evaluated for the inhibition of nitric oxide (NO) based on the accumulation of nitrite by activated macrophages in vitro. The results of NO inhibition in vitro as indicated by the reduction of nitrite are shown in Table 1. The results indicated that, under current experimental condition, all the four compounds showed better inhibition on NO production below at a cut-off concentration $(25 \mu \mathrm{M})$ in vitro as compared to resveratrol (1) $(40 \mu \mathrm{M})$, a natural polyphenol.

\subsubsection{In-Vitro Anti-Angiogenesis}

As an initial screen for biological activity, compounds 3 - 6 were evaluated for anti-angiogenesis in vitro against resveratrol. The $\mathrm{IC}_{50}$ values of anti-angiogenesis in vitro (by Kurabo software) were shown in Table 1. Representative images of the anti-angiogenesis were shown in Figure 2.

The results indicate that, under current experimental condition, all four resveratrol analogs are more effective anti-angiogenic agents in vitro as compared to resveratrol (1) $\left(\mathrm{IC}_{50}\right.$ at $47.7 \pm 1.1 \mu \mathrm{M}$ for HUVEC tube formation 
Table 1. $\mathrm{IC}_{50}$ values of in vitro anti-angiogenesis activity and NO.

\begin{tabular}{ccc}
\hline Compound & Anti-angiogenesis $\operatorname{IC}_{50}(\mu \mathrm{M})$ & NO inhibition IC $\mathrm{I}_{50}(\mu \mathrm{M})$ \\
\hline Control (Medium only) & N/A & N/A \\
\hline Resveratrol (1) & $47.7 \pm 1.1$ & 40 \\
$\mathbf{3}$ & $31.2 \pm 2.0$ & $<25$ \\
$\mathbf{4}$ & $18.8 \pm 1.3$ & $<25$ \\
$\mathbf{5}$ & $21.2 \pm 1.6$ & $<25$ \\
$\mathbf{6}$ & $19.9 \pm 2.3$ & $<25$ \\
\hline
\end{tabular}

inhibition); analogs 4, 5 and 6 (comparable $\mathrm{IC}_{50} \mathrm{~s}=18.8$ $\pm 1.3,21.2 \pm 1.6$, and $19.9 \pm 2.3 \mu \mathrm{M}$, respectively) appeared to be better than analog $3(31.2 \pm 2.0 \mu \mathrm{M})$.

\subsubsection{In-Vivo Carrageenan-Induced Edema Study}

A state of local acute inflammation was evoked by injecting $1 \%(\mathrm{w} / \mathrm{v}) \lambda$-carrageenan $(0.1 \mathrm{ml} / \mathrm{paw})$ s.c. into the plantar surface of the right hind paw of the rat, with the left paw (CMC treated) serving as a control. These analogs of resveratrol were evaluated for their in vivo anti-inflammatory activity at a single dose of $20 \mathrm{mg} / \mathrm{kg}$ using the carageenan-induced paw edema method in rats. In the vehicle-treated control group, the mean volume of the right hind paws increased by $0.71 \pm 0.07 \mathrm{ml}$ equivalent to $82.8 \%$ edema at $5 \mathrm{~h}$ after a carrageenan challenge (Figure 3). Our results obviously showed that the synthetic resveratrol analogs 3 - 6 exerted a striking anti-inflammatory effect with a significant reduction in swelling compared to resveratrol at rats. Among them, compound 4 manifested the greatest inhibition of $69.5 \%$ (paw edema, $0.21 \pm 0.06 \mathrm{ml}, P<0.05)$ after $5 \mathrm{~h}$.

\section{DISCUSSION}

\subsection{Synthesis}

At first, we prepared a key heterocyclic starting material, 3-ethyl-2-methylbenzothiazolium bromide (2), by a traditional reflux over $72 \mathrm{~h}$ in a low yield (32\%) and using a large amount of solvent. Alternatively, it appeared that microwave-assistant synthesis for compound 2 in higher yield $(57 \%)$ was more efficient and a saving to take a short time from $72 \mathrm{~h}$ to $5 \mathrm{~h}$ and to use a little amount solvent in a closed reaction system. Compound 2 was then used as the key starting material to react with the respective benzaldehydes to synthesize four heterocyclic resveratrol analogs 3 - 6 (Scheme 1 and Figure 1) in high yields about or over $90 \%$.

\subsection{Biological Evaluation}

\subsubsection{In-Vitro Nitric Oxide Inhibition (Based On Nitrite)}

The effects of the resveratrol analogs on cell viability were evaluated by RAW 264.7 macrophages at first. In the MTT assay, none of the analogs including resveratrol itself were toxic at various concentrations of 25, 50, 100, and up to $200 \mu \mathrm{M}$ on LPS-activated murine RAW 264.7 over $24 \mathrm{~h}$. The cell viability was in the $85 \%$ - 95\% range. On the basis of their non-toxicity to macrophages, the effects of the test compounds on NO production were further evaluated.

In order to evaluate the cytoprotective ability at the NO production level at the 24-h time point, one of the oxidative stress mediators, LPS-elicited RAW 264.7 macrophages were used in our experiments, The IC50 values are shown in Table 1, compounds 3 - 6 showed better inhibition on NO production below a cut-off concentration $(25 \mu \mathrm{M})$ in vitro currently as compared to resveratrol (1) $(40 \mu \mathrm{M})$, yet no more further screenings at NO inhibition were conducted but furthermore focused on anti-angiogenic testings.

Interestingly resveratrol itself has a paradoxical effect on the NO production in biological system that might be no effect at low concentration or short-term incubation with resveratrol but differentially boosts the NO production at high concentration over $50 \mu \mathrm{M}$ and after long-term use of resveratrol in a time- and concentration-dependent manner of endothelial cells. [23]

However, in macrophage cells (RAW 264.7), resveratrol for the inhibition of LPS-induced nitric oxide production by considering the involvement of an estrogen receptor was inhibited only when cells were treated with resveratrol prior to LPS-stimulation at a higher concentration of resveratrol [24].

\subsubsection{In-Vitro Anti-Angiogenesis}

It is now accepted that angiogenesis is central to maintaining and promoting rheumatoid arthritis (RA) and several studies in human have suggested that blocking angiogenesis during the course of RA may be of therapeutic benefits [25-27]. As an initial screen for anti-angiogenesis in vitro, compounds 3 - 6 compared to resveratrol were conducted. Among four resveratrol analogs, analogs 4, 5 and 6 are comparable and more effective anti-angiogenic agents in vitro than resveratrol (1), 
VEGF $10 \mathrm{ng} / \mathrm{ml}$ without treatment as a negative control

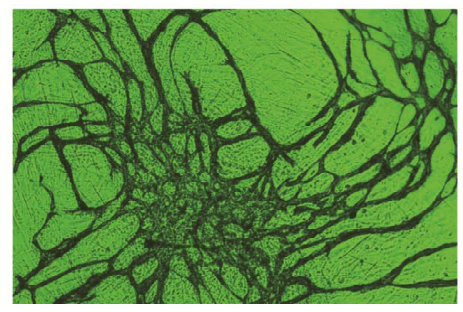

(a)

\begin{tabular}{|c|c|c|}
\hline \multirow{2}{*}{ Treatment compound } & \multicolumn{2}{|c|}{ Concentration } \\
\hline & $50 \mu \mathrm{M}$ & $10 \mu \mathrm{M}$ \\
\hline \multicolumn{3}{|c|}{ Resveratrol (as a positive con-trol) } \\
\hline \multicolumn{3}{|l|}{3} \\
\hline \multicolumn{3}{|l|}{4} \\
\hline \multicolumn{3}{|l|}{5} \\
\hline 6 & & \\
\hline
\end{tabular}

(b)

Figure 2. Representative images of the anti-angiogenesis $(40 \times)$ by the test compounds.

in consistence with an antiangiogenic action at $20-80$ $\mu \mathrm{M}$ for HUVEC tube formation on Matrigel [28] and appeared to be a little better than analog 3 .

\subsubsection{In-Vivo Carrageenan-Induced Edema Study}

Carrageenan-induced rat paw edema, an in-vivo model 
of acute inflammation for a variety of inflammatory and/or oxidative stress mediators with biphasic inflammatory nature, is the standard and most commonly used technique to screen inflammatory and/or anti-inflammatory activity. A state of local acute inflammation was evoked by injecting $1 \%(\mathrm{w} / \mathrm{v}) \lambda$-carrageenan $(0.1 \mathrm{ml} / \mathrm{paw})$ s.c. into the plantar surface of the right hind paw of the rat, with the left paw (vehicle treated) serving as a control. In the vehicle-treated control group, the mean volume of the right hind paws increased by $0.71 \pm 0.07 \mathrm{ml}$ at $5 \mathrm{~h}$ after a carrageenan challenge. Our results (Figure 3) obviously showed that the synthetic resveratrol analogs $3-6$ exerted a strikingly strong anti-inflammatory effect with a significant reduction in swelling compared to resveratrol at rats. Among them, compound 4 manifested the greatest inhibition of $69.5 \%$ (in turn of $25.3 \%$ paw edema, $0.21 \pm 0.06 \mathrm{ml}$, compared to vehicle control, $82.8 \%$ paw edema, $P<0.05$ ) after $5 \mathrm{~h}$.

On contrary, resveratrol has a slight anti-inflammatory activity at first 2-h but potentiate inflammatory action to boost rat paw edema after 3-h carrageenan challenge. Overall resveratrol has no anti-inflammatory effect that this result is consistent with the report by Gentilli et al. [29].

However, based on the results the antiinflammatory activities of compounds 3 - 6 were better as compared to resveratrol (1); compound 4 is the best among these four analogs. In the in vivo carrageenan-induced paw edema test, the anti-inflammatory activities of all the four analogs were better than that of resveratrol. Analog 4 reduced the edema to only about one of third that was the best among these four compounds. Therefore, these compounds may be worthy of further investigation as potential therapeutics.

\section{CONCLUSIONS}

In this study, we have made four novel analogs of resveratrol (1) basically by insertion of heterocyclic moieties into $(E)$-stilbene. These four new compounds were then studied for their biological properties.

In the in vitro studies, all the four analogs showed significantly better in vitro anti-angiogenesis effect as compared to resveratrol (1). Inhibition of LPS-induced NO production in vitro for each of these analogs was also significantly better than that of resveratrol (1).

In summary, this study showed that insertion of heterocyclic moieties into the $(E)$-stilbene core structure may be a new direction in term of modifying resveratrol and improving its biological properties. On the other hand, these preliminary biological properties do not guarantee that this type of analogs of resveratrol will result in actual therapeutics. Many more studies will have to be conducted in order to verify their potential to become

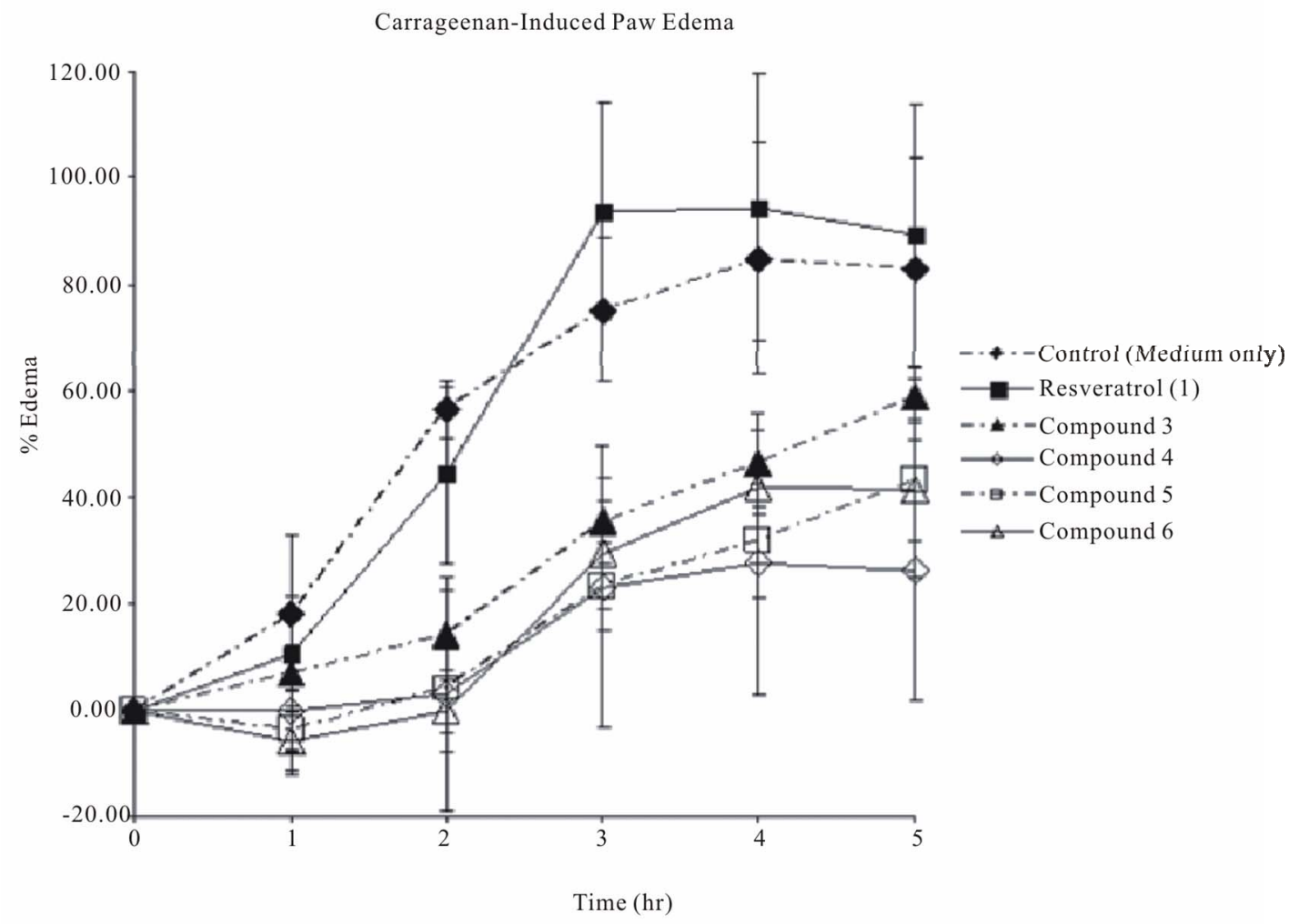

Figure 3. Anti-inflammatory activities of compounds 3 - 6 at $20 \mathrm{mg} / \mathrm{kg}$ i.p. single dose in carrageenan-induced paw edema model in rats $(n=3$ animals/group). Each value represents the average \pm SEM of 3 animals. 
suitable therapeutics.

\section{ACKNOWLEDGEMENTS}

We gratefully acknowledge the research grant supported from the Cheng-Hsin Rehabilitation Medical Center (CHGH 97-63), the Republic of China and JAK3 Pharma, Inc., Ann Arbor, Michigan, USA. We also gratefully thank for Dr. Ben Chen's helpful comments.

\section{REFERENCES}

[1] Bingham III, C.O. (2002) The pathogenesis of rheumatoid arthritis: Pivotal cytokines involved in bone degradation and inflammation. The Journal of Rheumatology, 29, 3-9.

[2] Nanjundaiah, S.M., Astry, B. and Moudgil, K.D. (2013) Mediators of inflammation-induced bone damage in arthritis and their control by herbal products. EvidenceBased Complementary and Alternative Medicine, 2013, $1-20$.

[3] Ziche, M. and Morbidelli, L. (2000) Nitric oxide and angiogenesis. Journal of Neuro-Oncology, 50, 139-148. doi: $10.1155 / 2013 / 518094$

[4] Cooke, J.P. and Losordo, D.W. (2002) Nitric oxide and angiogenesis. Circulation, 105, 2133-2135. doi:10.1161/01.CIR.0000014928.45119.73

[5] Tamura, T., Nakanishi, T., Kimura, Y., Hattori, T., Sasaki, K., Norimatsu, H., Takahashi, K. and Takigawa, M. (1996) Nitric oxide mediates interleukin-1-induced matrix degradation and basic fibroblast growth factor release in cultured rabbit articular chondrocytes: a possible mechanism of pathological neovascularization in arthritis. Endocrinology, 137, 3729-3737. doi:10.1210/en.137.9.3729

[6] Moulton, K.S., Heller, E., Konerding, M.A., Flynn, E., Palinski, W. and Folkman, J. (1999) Angiogenesis inhibitors endostatin or TNP-470 reduce intimal neovascularization and plaque growth in apolipoprotein E-deficient mice. Circulation, 99, 1726-1732. doi:10.1161/01.CIR.99.13.1726

[7] Matsunaga, T., Weihrauch, D.W., Moniz, M.C., Tessmer, J., Warltier, D.C. and Chilian, W.M. (2002) Angiostatin inhibits coronary angiogenesis during impaired production of nitric oxide. Circulation, 105, 2185-2191. doi:10.1161/01.CIR.0000015856.84385.E9

[8] Chun, Y.J., Kim, M.Y. and Guengerich, F.P. (1999) Resveratrol is a selective human cytochrome P450 1A1 inhibitor. Biochemical and Biophysical Research Communications, 262, 20-24. doi:10.1006/bbrc.1999.1152

[9] Orsini, F., Pelizzoni, F., Verotta, L., Aburjai, T. and Rogers, C.B. (1997) Isolation, synthesis, and antiplatelet aggregation activity of resveratrol 3-O-beta- $D$-glucopyranoside and related compounds. Journal of Natural Products, 60, 1082-1087. doi:10.1021/np970069t

[10] Arichi, H., Kimura, Y., Okuda, H., Baba, K., Kozawa, M. and Arichi, S. (1982) Effects of stilbene components of the roots of Polygonum cuspidatum Sieb. et Zucc. on lipid metabolism. Chemical Pharmaceutical Bulletin, 30, 17661770. doi:10.1248/cpb.30.1766
[11] Goldberg, D.M. (1996) More on antioxidant activity of resveratrol in red wine. Clinical Chemistry, 42, 113-114.

[12] Pace-Asciak, C.R., Hahn, S., Diamandis, E.P., Soleas, G. and Goldberg, D.M. (1995) The red wine phenolics transresveratrol and quercetin block human platelet aggregation and eicosanoid synthesis: Implications for protection against coronary heart disease. Clinica Chimica Acta, 235, 207-219. doi:10.1016/0009-8981(95)06045-1

[13] Inamori, Y., Inamori, Y., Kubo, M., Tsujibo, H., Ogawa, M., Saito, Y., Miki, Y. and Takemura, S. (1987) The ichthyotoxicity and coronary vasodilator action of 3,3'-dihydroxy-alpha,beta-diethylstilbene. Chemical and Pharmaceutical Bulletin, 35, 887-890. doi:10.1248/cpb.35.887

[14] Tang, L.L., Gao, J.S., Chen, X.R. and Xie, X. (2006) Inhibitory effect of resveratrol on the proliferation of synoviocytes in rheumatoid arthritis and its mechanism in vitro. Zhong Nan Da Xue Xue Bao Yi Xue Ban, 31, 528-533.

[15] Elmali, N., Baysal, O., Harma, A., Esenkaya, I. and Mizrak, B. (2007) Effects of resveratrol in inflammatory arthritis. Inflammation, 30, 1-6. doi:10.1007/s10753-006-9012-0

[16] Bi, X.L., Yang, J.Y., Dong, Y.X., Wang, J.M., Cui, Y.H., Ikeshima, T., Zhao, Y.Q. and Wu, C.F. (2005) Resveratrol inhibits nitric oxide and TNF-alpha production by lipopolysaccharide-activated microglia. International Immunopharmacology, 5, 185-193.

doi:10.1016/j.intimp.2004.08.008

[17] Tseng, S.H., Lin, S.M., Chen, J.C., Su, Y.H., Huang, H.Y., Chen, C.K., Lin, P.Y. and Chen, Y. (2004) Resveratrol suppresses the angiogenesis and tumor growth of gliomas in rats. Experimental Therapeutic Preclinical Pharmacology, 10, 2190-2202.

[18] Ghai, G., Chen, K.Y., Rosen, R.T., Wang, M., Telang, N., Lipkin, M. and Ho, C.-T. (2004) Resveratrol analogs for prevention of disease, US Patent 6790869. The State University of New Jersey, Rutgers.

[19] Pettit, G.R., Grealish, M.P., Jung, M.K., Hamel, E., Pettit, R K., Chapuis, J.C. and Schmidt, J.M. (2002) Antineoplastic agents. 465. Structural modification of resveratrol: Sodium resverastatin phosphate. Journal of Medicinal Chemistry, 45, 2534-2542. doi:10.1021/jm010119y

[20] Ohyama, M., Ohyama, M., Tanaka, T., Ito, T., Iinuma, M., Bastow, K.F. and Lee, K.H. (1999) Antitumor agents 200. Cytotoxicity of naturally occurring resveratrol oligomers and their acetate derivatives. Bioorganic Medicinal Chemistry Letters, 9, 3057-3060. doi:10.1016/S0960-894X(99)00520-X

[21] Gosslau A., Chen, M., Ho, C.T. and Chen, K.Y. (2005) A methoxy derivative of resveratrol analogue selectively induced activation of the mitochondrial apoptotic pathway in transformed fibroblasts. British Journal of Cancer, 92, 513-521.

[22] Gosslau, A., Pabbaraja, S., Knapp, S. and Chen, K.Y. (2008) Trans- and cis-stilbene polyphenols induced rapid perinuclear mitochondrial clustering and p53-independent apoptosis in cancer cells but not normal cells. European Journal of Pharmacology, 587, 25-34. doi:10.1016/j.ejphar.2008.03.027

[23] Takahashi, S., Uchiyama, T. and Toda, K. (2009) Differ- 
ential effect of resveratrol on nitric oxide production in endothelial f-2 cells. Biological and Pharmaceutical Bulletin, 32, 1840-1843. doi:10.1248/bpb.32.1840

[24] Cho, D.I., Koo, N.Y., Chung, W.J., Kim, T.S., Ryu, S.Y., Im, S.Y. and Kim, K.M. (2002) Effects of resveratrol-related hydroxystilbenes on the nitric oxide production in macrophage cells: Structural requirements and mechanism of action. Life Sciences, 71, 2071-2082. doi:10.1016/S0024-3205(02)01971-9

[25] FitzGerald, O., Soden, M., Yanni, G., Robinson, R. and Bresnihan, B. (1991) Morphometric analysis of blood vessels in synovial membranes obtained from clinically affected and unaffected knee joints of patients with rheumatoid arthritis. Annals of the Rheumatic Diseases, 50, 792-796. doi:10.1136/ard.50.11.792

[26] Ceponis, A., Konttinen, Y.T., Imai, S. Tamulaitiene, M., Li, T.F., Xu, J.W., Hietanen, J., Santavirta, S. and Fassbender, H.G. (1998) Synovial lining, endothelial and inflammatory mononuclear cell proliferation in synovial membranes in psoriatic and reactive arthritis: A comparative quantitative morphometric study. British Journal of Rheumatology, 37, 170-178. doi:10.1093/rheumatology/37.2.170

[27] Walsh, D.A., Wade, M., Mapp, P.I. and Blake, D.R. (1998) Focally regulated endothelial proliferation and cell death in human synovium. American Journal of Pathology, 152, 691-702.

[28] Cao, Y., FU, Z.-D., Wang, F., Liu, H.-Y. and Han, R. (2005) Anti-angiogenic activity of resveratrol, a natural compound from medicinal plants. Journal of Asian Natural Products Research, 7, 205-213. doi:10.1080/10286020410001690190

[29] Gentilli, M., Mazoit, J.X., Bouaziz, H., Fletcher, D., Casper, R.F., Benhamou, D. and Savouret, J.-F. (2001) Resveratrol decreases hyperalgesia induced by carrageenan in the rat hind paw. Life Science, 68, 1317-1321. doi:10.1016/S0024-3205(00)01018-3 